\title{
CONTROLE DE PLANTAS DANINHAS COM HERBICIDA GLYPHOSATE UTILIZANDO DIFERENTES PONTAS DE PULVERIZAÇÃO
}

\section{WEED CONTROL WITH HERBICIDE GLYPHOSATE USING DIFFERENT NOZZLES}

\author{
Murilo Peres de Castro BARROS ${ }^{1}$ \\ Cristiane Gonçalves de MENDONÇA ${ }^{2}$ \\ Leandro TROPALDI ${ }^{3}$
}

\section{RESUMO}

A dessecação das plantas daninhas no sistema de plantio direto em áreas de pousio é essencial para manter a massa seca na superfície do solo no cultivo de verão. Para tanto, a seleção das pontas de pulverização utilizada na aplicação do herbicida deve ser feita visando o controle de plantas daninhas e minimizando a possibilidade de deriva. Assim, este trabalho teve como objetivo avaliar o efeito de diferentes pontas de pulverização no controle de plantas daninhas dessecadas com diferentes doses do herbicida glyphosate. O delineamento experimental foi o de blocos ao acaso com treze tratamentos e quatro repetições. A distribuição dos tratamentos foi em esquema fatorial $3 \times 4$ (doses de glyphosate $\mathrm{x}$ ponta de pulverização) e a testemunha. As doses de glyphosate foram: 480,720 e $960 \mathrm{~g}$ i.a. ha ${ }^{-1}$. As pontas de pulverização utilizadas foram: leque - XR 110 02; leque com indução de ar - Al 11002 VS; pré-orifício - TT 11002 VP e duplo leque - TJ-60 11002 VS. O experimento foi conduzido no campo experimental da UEMS/Unidade de Cassilândia durante vinte e oito dias com avaliações de controle de plantas daninhas aos 7, 14, 21 e 28 dias após a aplicação. Com exceção da ponta XR 110 02, as demais pontas (AI, TT e TJ-60) apresentaram melhor controle de plantas daninhas até os 21 DAA. Entretanto, aos 28 DAA a Al não diferiu estatisticamente da XR na avaliação do controle de plantas daninhas. As doses de glyphosate mais eficientes para a dessecação das plantas daninhas foram as superiores a $720 \mathrm{~g}$ i.a. ha ${ }^{-1}$.

Palavras-Chave: tecnologia de aplicação, volume de calda, bicos.

\section{ABSTRACT}

This work aimend to evaluate the affect of different spray associated with different doses of glyphosate in control weeds dried for Summer planting. The experimental design was a randomized block design with thirteen treatments and four replications. The doses of glyphosate were 480,720 and $960 \mathrm{~g}$ i.a. ha ${ }^{-1}$. The nozzles used were: type range - XR; type range air induction - Al; pre-orifice type TT; and type double fan TJ. The experiment was conducted in the field experimental UEMS, Unit Cassilândia during twenty-eight days with ratings of control at 7, 14, 21 and 28 days after application. A selection of spray nozzles in the use of graut glyphosate was performed by assessing the weed control of area. Aside from the type of XR, the other ends Al TT, and TJ, showed better weed control until 21 DAA. However, at 28 DAA the Al did not differ from the XR evaluations of weed control. Doses of ghyphosate more efficient for the weed control were higher than $720 \mathrm{~g}$ i.a. ha ${ }^{-1}$. Key words: method application, sprayer volume.

${ }^{1}$ Eng. Agr., Autônomo, Goiânia - GO, e-mail: murilopcbarros@hotmail.com

${ }^{2}$ Eng $^{\text {a }}$. Agra ., Dra., Prof ${ }^{a}$. Assistente, Unidade de Aquidauana, UEMS/Aquidauana-MS. E-mail: cgmendon@terra.com.br

${ }^{3}$ Eng. Agr., M. Sc., Doutorando do Curso de Proteção de Plantas da Universidade Estadual Paulista Botucatu, SP. 
BARROS, M. P. C. et al. Controle de plantas daninhas...

\section{INTRODUÇÃO}

Após a colheita da cultura de verão, a ausência de culturas de sucessão propicia o desenvolvimento de espécies daninhas, necessitando de controle para o inicio da próxima safra (Carmona, 1992; Carvalho \& Sodré Filho, 2000). O glyphosate é um herbicida dessecante que no sistema de semeadura direta tem exercido um efetivo controle de um grande número de plantas daninhas mono e dicotiledôneas, tanto perenes como anuais (Santos et al., 2001). Assim, são amplamente utilizados em operações de dessecação em pós-emergência das plantas daninhas e antes da semeadura e emergência das culturas (Kruse et al., 2000), pois não possuem ação residual, já que os compostos são fortemente adsorvidos ao solo (Rodrigues \& Almeida, 1998).

O glyphosate é um herbicida sistêmico e não -seletivo que quando absorvido via foliar e translocado até as raízes promovendo a morte total das plantas daninhas (Landers, 1994). Uma vez que seu mecanismo de ação inibi a enzima EPSPS na rota de síntese dos aminoácidos aromáticos fenilalanina, tirosina e triptofano (Rodrigues \& Almeida, 2005). Assim quando ocorre a interrupção da produção dos aminoácidos, alteram consequentemente a divisão celular nas regiões meristemáticas da planta (Hess, 1994).

Resultados de campo e casa de vegetação indicam que herbicidas aplicados sobre a folhagem durante períodos de seca não são tão efetivos quanto aqueles aplicados quando a umidade do solo está adequada (Boydston, 1990; Peregoy et al., 1990). Segundo Basler et al. (1961) e Levene \& Owen (1995), a baixa eficiência dos herbicidas aplicados durante períodos de déficit hídrico se deve, principalmente, à redução na absorção desses compostos. Solos com falta de água apresentam plantas mais secas o que dificulta a absorção e translocação do produto na planta, uma vez que as folhas ficam mais retorcidas, portanto nos períodos de escassez de chuva o controle será menos eficiente, do que em períodos de maior precipitação pluviométrica.

A umidade do solo, a temperatura e a umidade relativa do ar interferem no comportamento dos herbicidas nas plantas (Devine et al., 1983). A estrutura molecular, a utilização de adjuvantes e as condições climáticas influenciam, de forma significativa, nos processos de absorção e translocação do glifosato (Kruse et al., 2000).

A busca por maior eficiência dos equipamentos, com conseqüente diminuição dos custos de aplicação, tem mostrado uma tendência de os agricultores diminuírem os volumes de calda aplicada (Silva, 1999). Isto porque algumas vezes com um adequado manejo e/ou sob certas condições de ambiente, as doses dos herbicidas podem ser reduzidas e, ainda, prover controle eficiente das plantas daninhas (Devine et al., 1991; Klingaman et al., 1992; Boström \& Fogelfors, 2002). No entanto, o volume aplicado deve ser o mais uniforme possível, sob pena de exigirem aplicações adicionais para compensar os pontos, ou faixas, que receberam quantidades menores (Perecin et al., 1998). Ainda convém lembrar que em certas condições de clima e período o objetivo de controle a redução da dosagem podem acarretar em um ineficiente controle das infestantes. Assim a tecnologia de aplicação de defensivos agrícolas vem trabalhando a fim de oferecer mais possibilidade de se trabalhar com mais exatidão na escolha e opção da técnica que seja capaz de atingir o alvo de interesse, com a utilização de novas pontas. E muitas vezes, o tratamento é eficaz, porém, os mesmos resultados poderiam ser obtidos com doses muito inferiores, utilizandose melhor tecnologia de aplicação e equipamentos (Fernandes, 1997).

O conhecimento das condições de trabalho e o desempenho das pontas de pulverização, para Christofoletti (1999) são fundamentais quando se busca uma aplicação adequada, eficiente e econômica. Womac et al. (1997) afirmam que a escolha e o uso adequado de pontas de pulverização constituem passos importantes para a melhoria das condições de precisão e segurança na aplicação de produtos fitossanitários.

Sendo assim o presente trabalho teve como objetivo avaliar o efeito de diferentes pontas de pulverização associado a diferentes doses do herbicida glyphosate no controle de plantas daninhas.

\section{MATERIAL E MÉTODOS}

$\mathrm{O}$ experimento foi conduzido na área experimental da Universidade Estadual de Mato Grosso do Sul - Unidade Universitária de Cassilândia, localizada no município de Cassilândia-MS, cujo as coordenadas geográficas são de $19^{\circ} 05^{\prime} \mathrm{S}, 5^{\circ} 56^{\prime} \mathrm{W}$, com altitude de $471 \mathrm{~m}$. Na área não houve qualquer tipo de manejo de plantas daninhas nos seis meses que antecederam o experimento. $O$ delineamento experimental utilizado foi em blocos ao acaso com quatro repetições, com os tratamentos dispostos em esquema fatorial $4 \times 3$ (4 pontas de pulverização $\times 3$ dosagens do herbicida glyphosate), sendo as doses do herbicida 480, 720 e 960 g i.a. ha ${ }^{-1}$ e havendo ainda a testemunha sem aplicação. O produto comercial utilizado foi o Gliz 480 SL® (480 g de equivalente ácido por litro de produto comercial). A área de cada parcela foi de $9 \mathrm{~m}^{2}(3 \times 3 \mathrm{~m})$. Na Tabela 1 estão descritos os tratamentos utilizados no experimento.

A aplicação foi realizada no dia 25/08/2008 com pulverizador costal pressurizado com $\mathrm{CO}_{2}$, com barra de pulverização contendo seis pontas espaçadas $0,50 \mathrm{~m}$, com vazão de $0,450 \mathrm{~L} \mathrm{~min}{ }^{-1}$, utilizando o volume de calda de $150 \mathrm{~L} \mathrm{ha}^{-1}$, e uma velocidade de deslocamento de $1 \mathrm{~m} \mathrm{~s}^{-1}$, para todos os tratamentos a uma altura de $0,5 \mathrm{~m}$ do solo. As pontas XR 110 02, TT 11002 VP e TJ-60 11002 foram regulada com pressão de 0,95 bar e a ponta Al 11002 VS com pressão de 0,97 bar. A aplicação das caldas utilizando a ponta XR 11002 foi as $08 \mathrm{~h} 43 \mathrm{~min}$ com temperatura de $31,1^{\circ} \mathrm{C}$ e umidade relativa do ar de $27 \%$. Os tratamentos que utiliza- 
BARROS, M. P. C. et al. Controle de plantas daninhas...

ram a ponta Al 11002 VS foram aplicados as $17 \mathrm{~h} 00 \mathrm{~min}$, com temperatura de $30,6{ }^{\circ} \mathrm{C}$ e umidade relativa de $25 \%$. Na aplicação com a ponta TT 110 02 VP a temperatura era de $30,8 \circ \mathrm{C}$ e umidade relativa $25 \%$ e o horário às $17 \mathrm{~h} 20 \mathrm{~min}$. As $17 \mathrm{~h} 45 \mathrm{~min}$ aplicou-se a calda com a ponta TJ-60 11002 VS com temperatura de $28,0{ }^{\circ} \mathrm{C}$ e umidade relativa de $28 \%$. Diariamente foram monitorados os dados meteorológicos (precipitações, temperaturas máxima e mínima, umidade relativa máxima e mínima), apresentados na Figura 1.

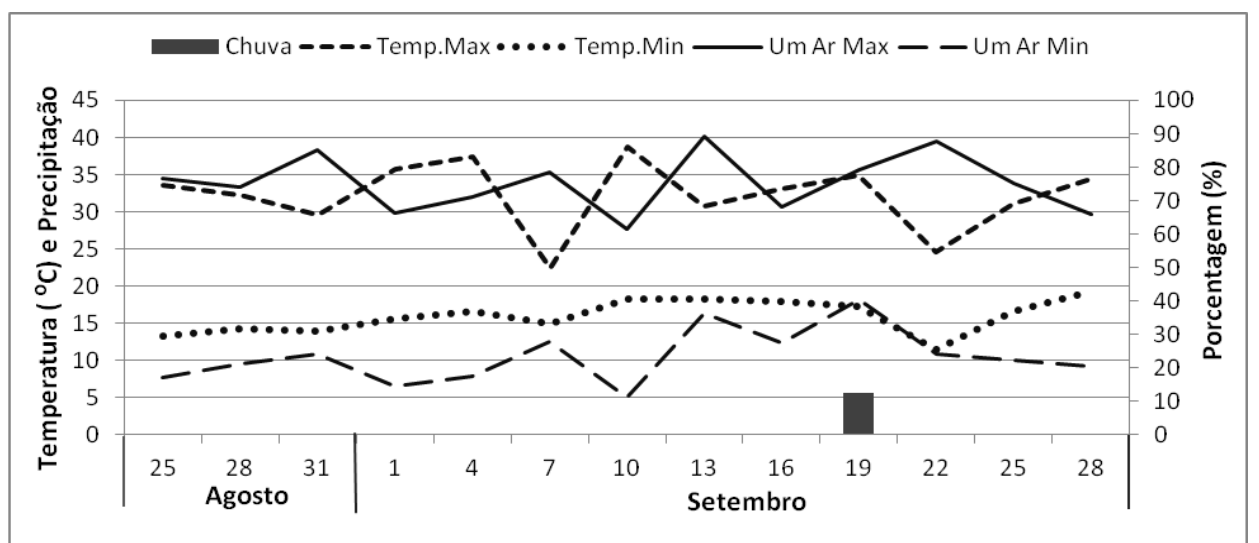

Figura 1 - Dados meteorológicos do período de condução do experimento (agosto e setembro de 2008). UEMS, Cassilândia- MS, 2009.

Tabela 1 - Tratamentos utilizados no experimento. UEMS, Cassilândia - MS, 2009.

\begin{tabular}{cll}
\hline Tratamentos & Pontas de pulverização & Dosagem $\left(\mathrm{g}\right.$ i.a. ha $\left.^{-1}\right)$ \\
\hline 1 & Tipo leque & 480 \\
2 & XR 110 02 & 720 \\
3 & $(\mathrm{XR})$ & 960 \\
\hline 4 & Tipo leque com indução de ar & 480 \\
5 & Al 110 02 VS & 720 \\
6 & (Al) & 960 \\
\hline 7 & Tipo pré-orifício & 480 \\
8 & TT 110 02 VP & 720 \\
9 & (TT) & 960 \\
\hline 10 & Tipo duplo leque & 480 \\
11 & TJ-60 110 02 VS & 720 \\
12 & (TJ) & 960 \\
\hline 13 & Testemunha (sem herbicida) & \\
\hline
\end{tabular}

A comunidade infestante da área foi levantada antes das aplicações dentro de cada parcela com a contagem e identificação das espécies numa área de um metro quadrado (gabarito de ferro de $1 \times 1 \mathrm{~m}$, lançado aleatoriamente dentro de cada parcela). Na última avaliação de controle estas plantas foram coletadas e determinada a massa seca, com a secagem em estufa de circulação forçada de ar a $65^{\circ} \mathrm{C}$ até peso constante.

A eficácia de controle foi determinada em função da avaliação visual da porcentagem de controle, utilizando notas, considerando-se $100 \%$ total morte da planta e $0 \%$ nenhum controle, todos comparados com uma testemunha sem aplicação. Estas avaliações foram realizadas $7,14,21$ e 28 dias após a aplicação (DAA).

Os resultados obtidos foram submetidos à análise de variância pelo teste $F$. As médias dos tratamentos componentes do fatorial foram comparadas entre si pelo teste de Tukey no nível de $5 \%$ de probabilidade através do programa estatístico Sistema para Análise de Variância - SISVAR (Ferreira, 2000). 
BARROS, M. P. C. et al. Controle de plantas daninhas...

\section{RESULTADOS E DISCUSSÃO}

A área experimental apresentou espécies de plantas daninhas características da região, sendo as maiores porcentagem de ocorrência das seguintes espécies: malva-branca (Walteria indica L.) com $30,4 \%$, capim-carrapicho (Cenchrus echinatus L.) 25,9\%, gervão-branco (Croton glandulosus L.) $12,2 \%$, tiririca (Cyperus esculentus L.) 9,2\%, carrapicho-do-mato (Urena lobata L.) 10,1\%, trapoeraba (Commelina benghalensis L.) 2,3\%, corda -de -viola (Merremia cissoides (LAM.) Hallier f.) 1,9\%, agriãozinho (Synedrellopsis grisebachii Hieron.) 1,6\% e guaxuma (Sida santaremnensis $\mathrm{H}$. Monteiro) com $1,2 \%$.

A Tabela 2 apresenta os valores de F e níveis de significância obtidos na análise de variância para porcentagem de controle de plantas daninhas, analisando o efeito das pontas de pulverização, das diferentes doses, a a interação entre pontas e doses, e o efeito dos blocos aos 7, 14, 21 e 28 dias após a aplicação (DAA). Onde se observou diferença significativa para a variável ponta de pulverização em todos os períodos avaliados atentando-se aos 7 DAA, pois o teste $F$ foi significativo a $5 \%$ e nos demais períodos avaliados significativos a $1 \%$ de probabilidade. Na fonte de variação doses de glyphosate, notou-se significância em todos os períodos. Já a interação pontas de pulverização versus doses de glyphosate apenas aos 28 DDA obteve significância $(P<0,01)$, no qual períodos anteriores não demostraram diferenças.

Tabela 2 - Valores de F e nível de significância obtido na análise de variância para porcentagem de controle de plantas daninhas aos 7, 14, 21 e 28 DAA. UEMS, Cassilândia - MS, 2009.

\begin{tabular}{lcccc}
\hline Fontes de variação & \multicolumn{3}{c}{ Valores de F } \\
& 7 DAA & 14 DAA & 21DAA & 28 DAA \\
\hline Pontas de pulverização (P) & $3,53^{*}$ & $4,84^{* \prime}$ & $4,43^{* \prime}$ & 6,94 \\
Doses de glyphosate (D) & $157,01^{* *}$ & $157,17^{* *}$ & $148,85^{* *}$ & $165,01^{* *}$ \\
Interação (P X D) & $1,35^{\text {ns }}$ & $1,58^{\text {ns }}$ & $1,97^{\text {ns }}$ & $3,20^{* *}$ \\
Bloco & $3,19^{*}$ & $2,98^{*}$ & $1,20^{\text {ns }}$ & $0,88^{\text {ns }}$ \\
\hline
\end{tabular}

${ }^{* *}$ Significativo a $1 \%$ de probabilidade, pelo teste $\mathrm{F}$; ${ }^{*}$ Significativo a $5 \%$ de probabilidade, pelo teste $\mathrm{F}$. ns - Não significativo.

Para o efeito de blocos o teste foi significativo aos 7 e 14 dias após a aplicação e após estes períodos não foi detectado diferenças. Para tanto, confirma-se a necessidade da realização deste experimento no delinamento de blocos casualizados.

A Tabela 3 apresenta os valores médios de porcentagem de controle de plantas daninhas em função dos períodos avaliados após aplicação quando utilizados as diferentes pontas de pulverização analisadas pelo teste de Tukey $(P<0,05)$. A ponta $\mathrm{XR}$ apresentou menor porcentagem de controle em relação às pontas $\mathrm{Al}$, TT e TJ-60 aos 7 DAA, porém não houve diferença significativa entre as pontas XR, TT e TJ-60 aos 7 DAA, mas houve diferença significativa entre as pontas $\mathrm{XR}$ e $\mathrm{Al}$ aos 7 DAA.

Tabela 3 - Valores médios de porcentagem de controle de plantas daninhas aos 7, 14, 21 e 28 DAA em função de diferentes pontas de pulverização. UEMS, Cassilândia - MS, 2009.

\begin{tabular}{clccc}
\hline Pontas de Pulverização & \multicolumn{4}{c}{ \% de controle de plantas daninhas } \\
& 7 DAA & 14 DAA & 21DAA & 28 DAA \\
\hline XR & $27,07 \mathrm{~b}$ & $34,37 \mathrm{~b}$ & $36,56 \mathrm{~b}$ & $40,00 \mathrm{~b}$ \\
Al & $34,38 \mathrm{a}$ & $43,43 \mathrm{a}$ & $46,56 \mathrm{a}$ & $49,68 \mathrm{ab}$ \\
TT & $32,81 \mathrm{ab}$ & $45,93 \mathrm{a}$ & $47,81 \mathrm{a}$ & $54,68 \mathrm{a}$ \\
TJ-60 & $33,13 \mathrm{ab}$ & $43,12 \mathrm{a}$ & $47,18 \mathrm{a}$ & $54,68 \mathrm{a}$ \\
\hline
\end{tabular}

Médias seguidas de letras minúsculas na coluna diferem entre si a $5 \%$ de probabilidade pelo teste de Tukey.

A porcentagem de controle de plantas daninhas com a ponta XR aos 14 DAA foi menor do que as pontas Al, TT e TJ-60, diferindo estatisticamente pelo teste de Tukey $(P<0,05)$ entre a ponta $X R$ com as demais. Já as pontas AI, TT e TJ-60, comparadas entre si não apresentarem diferença significativa pelo teste de Tukey $(P<0,05)$. Permanecendo o mesmo comportamento quando realizada avaliação aos 21 DAA. Em experimento visando a eficácia biologia de diferentes pontas de pulverização utilizando o herbicida phenmedipham em diferentes doses no controle de Brassica napus, Jensen e Lund (2006) verificaram que a ponta de jato duplo TJ-60 4002 obteve melhor controle do que a ponta leque 110 02, corroborando com os resultados de controle de plantas daninhas obtidos aos 14, 21 e
28 DAA.

Aos 28 DAA não ocorreu diferença significativa entre as pontas XR e Al, porém observou diferença significativa entre a ponta $X R$ quando comparadas com as pontas TT e TJ-60. E a ponta Al também não apresentou diferença significativa quando comparada com as pontas TT e TJ-60. A eficiência do herbicida glyphosate não foi afetada em função da utilização de pontas que produzem gotas pequenas, como a TJ-60 e por pontas que produzam gotas maiores, com ou sem a indução de ar, como a $\mathrm{Al}$ e a TT, respectivamente. Para tanto, a molécula consegue bons níveis de eficiência independente da cobertura ou deposição, que seria maior nos tratamentos com as pontas TJ-60. 
No geral observou-se baixa eficiência de controle das plantas daninhas, visto que os dados quando confrontados com as condições meteorológicas e o período em que o experimento foi realizado, confirma-se as afirmações Boydston, 1990; Peregoy et al., 1990; Basler et al.1961; Levene e Owen,1995) que todos se referem a menor eficiência do glyphosate quando sua aplicação é realizada em condições de clima seco e comunidade com plantas mais desenvolvidas apresentando sinais de restrição hídrica.

A Tabela 4 apresenta os valores médios de porcentagem de controle de plantas daninhas nos períodos avaliados em função de diferentes doses de glyphosate.

Tabela 4 - Valores médios de porcentagem de controle de plantas daninhas aos 7, 14, 21 e 28 DAA em função de doses de glyphosate. UEMS, Cassilândia - MS, 2009.

\begin{tabular}{lcccc}
\hline Doses de glyphosate & \multicolumn{4}{c}{ \% de controle de plantas daninhas } \\
(gramas i.a. ha $^{-1}$ ) & 7 DAA & 14 DAA & 21DAA & 28 DAA \\
\hline Testemunha & $0,00 \mathrm{c}$ & $0,00 \mathrm{c}$ & $0,00 \mathrm{c}$ & $0,00 \mathrm{c}$ \\
480 & $35,94 \mathrm{~b}$ & $45,00 \mathrm{~b}$ & $47,50 \mathrm{~b}$ & $57,50 \mathrm{~b}$ \\
720 & $46,13 \mathrm{a}$ & $60,00 \mathrm{a}$ & $62,50 \mathrm{a}$ & $70,93 \mathrm{a}$ \\
960 & $45,32 \mathrm{a}$ & $61,87 \mathrm{a}$ & $68,12 \mathrm{a}$ & $70,62 \mathrm{a}$ \\
\hline
\end{tabular}

Médias seguidas de letras minúsculas na coluna diferem entre si a $5 \%$ de probabilidade pelo teste de Tukey.

Para os valores médios de porcentagem de controle de plantas daninhas em função de diferentes doses de glyphosate, a testemunha (dose zero) uma vez que a aplicação de herbicida nestas parcelas, assim evidentemente que todos as outras combinações de pontas e doses expressam efeito quando comparadas com a testemunha.

Percebeu-se diferença entre a dose $480 \mathrm{~g}$ i.a. ha $^{-1}$ comparando-a com as doses 720 e $960 \mathrm{~g}$ i.a. $\mathrm{ha}^{-1}$ nos períodos avaliados, tendo a dose $480 \mathrm{~g}$ i.a. ha ${ }^{-1}$ menor controle de plantas daninhas do que as doses 720 e $960 \mathrm{~g}$ i.a. ha ${ }^{-1}$. Agora as doses 720 e $960 \mathrm{~g}$ i.a. ha ${ }^{-1}$ não apresentaram diferença entre si controle de plantas daninhas nos períodos avaliados. Sikkema et al. (2008) também observaram diferenças estatísticas entre a maior dose de bentazon $\left(1080 \mathrm{~g}\right.$ i.a. ha $\left.{ }^{-1}\right)$ e a menor dose (540 g i.a. ha $\left.{ }^{-1}\right)$ no controle Chenopodium album com aplicação da calda com pontas tipo leque e pontas com indução de ar. Entretanto, não verificaram diferenças estatísticas entre as pontas usadas na aplicação. No controle de Abutilon theophrasti, a maior dose (1080 g i.a. ha $^{-1}$ ) também apresentou diferença estatística dos tratamentos com a menor dose de $540 \mathrm{~g}$ i.a. ha
1 . Sendo assim notou-se que os herbicida glyphosate pode ser aplicado utilizando pontas de pulverização Al, TT e TJ-60 sem perder eficiência de controle, considerando as condições de condução do trabalho e que a utilização da ponta de XR reduz a eficiência de controle de plantas daninhas utilizando o herbicida glyphosate na dessecação.

O desdobramento da interação das pontas de pulverização versus doses de glyphosate na avaliação realizada aos 28 dias após a aplicação (Tabela 5) proporcionou controle das plantas daninhas, uma vez que se diferiram da testemunha. No entanto analisando a dose de $480 \mathrm{~g}$ i.a. ha ${ }^{-1}$, observou-se que entre as pontas XR e Al e também entre as pontas TT e TJ-60 não proporcionaram alterações na porcentagem de controle das plantas daninhas e quando faz correlação entre as pontas TT e TJ-60 e as comparas com a ponta XR notou-se diferenças. Para a dose $720 \mathrm{~g}$ i.a. ha ${ }^{-1}$ não houve influencia da ponta de pulverização no controle das plantas daninhas. $\mathrm{Na}$ dose $960 \mathrm{~g}$ i.a. ha ${ }^{-1}$ detectou diferença apenas entre a ponta $\mathrm{XR}$ e as pontas $\mathrm{Al}$, TT e TJ-60, sendo que as ultimas não diferiram entre si.

Tabela 5 - Desdobramento da interação Pontas de pulverização x Doses de glyphosate aos 28 DAA. UEMS, Cassilândia - MS, 2009.

\begin{tabular}{ccccc}
\hline Pontas de & \multicolumn{4}{c}{ Doses de glyphosate $\left(\mathrm{g}\right.$ i.a. ha $^{-1}$ ) } \\
Pulverização & Testemunha (0) & 480 & 720 & 960 \\
\hline XR & $0,00 \mathrm{aC}$ & $40,00 \mathrm{c}$ B & $66,25 \mathrm{abA}$ & $53,75 \mathrm{bAB}$ \\
Al & $0,00 \mathrm{aC}$ & $53,75 \mathrm{bcB}$ & $63,75 \mathrm{aAB}$ & $81,25 \mathrm{aA}$ \\
TT & $0,00 \mathrm{aC}$ & $60,00 \mathrm{abB}$ & $85,00 \mathrm{aA}$ & $73,75 \mathrm{aAB}$ \\
TJ-60 & $0,00 \mathrm{aB}$ & $76,25 \mathrm{aA}$ & $68,75 \mathrm{abA}$ & $73,75 \mathrm{aA}$ \\
\hline
\end{tabular}

Médias seguidas de letras minúsculas na coluna diferem entre si pelo teste de Tukey $(P<0,05)$. Médias seguidas de letras maiúsculas na linha diferem entre si pelo teste de Tukey $(P<0,05)$. 
BARROS, M. P. C. et al. Controle de plantas daninhas...

Efetuando a análise individual das pontas de pulverização em função das doses de glyphosate encontrou-se comportamentos diferenciados para elas. $\mathrm{Na}$ análise da ponta $\mathrm{XR}$, pode-se observar que houve diferença significativa entre a testemunha e as demais doses, e entre as doses do glyphosate observou-se também diferença na comparação das doses 480 e $720 \mathrm{~g}$ i.a. ha $^{-1}$ quando comparadas entre si.

Para a ponta Al em função de diferentes doses, assim como a testemunha quando comparadas com as demais, a comparação entre as doses 480 e 720 g i.a. ha ${ }^{-1}$ não foi detectado diferença. No entanto, constatou-se diferença quando foi comparado as doses de 480 e $960 \mathrm{~g}$ i.a. ha ${ }^{-1}$ sendo que a ultima promoveu uma melhor porcentagem de controle das plantas daninhas em relação às outras. Avaliando o efeito de pontas de pulverização na deposição de glyphosate em braquiária, Costa et al. (2008) observou maiores depósitos nas pontas IA, fator interessante que pode contribuir na maior eficiência no controle, mas em contrapartida contatou também menores uniformidades do depósito, sugerindo maiores estudos a respeito.
$\mathrm{Na}$ análise da ponta TT, além da testemunha, ou seja, dose zero do glyphosate podemos observar diferença entre as outras doses analisadas. Assim, encontrou-se também diferenças na comparação das doses 480 e $720 \mathrm{~g}$ i.a. ha ${ }^{-1}$, porém entre a dosagem de 720 e 960 g i.a. ha ${ }^{-1}$ não diferiram, o que permite especular que para a condição do experimento (condição climática, comunidade infestante, densidade, idade, etc.) a utilização de $720 \mathrm{~g}$ i.a. ha ${ }^{-1}$ para dessecação obtém bons níveis de controle. Para a ponta TJ-60, analisando apenas as doses com o herbicida glyphosate não foi constatado diferenças entre elas, com exceção da dose zero.

A Tabela 6 apresenta os valores de F e níveis de significância obtidos na análise de variância para matéria seca de plantas daninhas aos $28 \mathrm{DAA}$. Não houve diferença significativa na massa seca quando se comparou o efeito de pontas de pulverização e o efeito das doses. A interação pontas de pulverização versus doses de glyphosate também não foi significativa para esta variável, porém para efeito de blocos o teste foi significativo pelo teste $F$.

Tabela 6 - Valores de F e nível de significância obtido na análise de variância para massa seca de plantas daninhas aos 28 DAA. UEMS, Cassilândia - MS, 2009.

\begin{tabular}{lc}
\hline Fontes de variação & Massa seca de plantas daninhas $(\mathrm{g})$ \\
\hline Pontas & $0,92^{\text {ns }}$ \\
Doses & $1,32^{\text {ns }}$ \\
Interação (P X D) & $0,70^{\text {ns }}$ \\
Bloco & $18,49^{\text {** }}$ \\
\hline CV $(\%)$ & 33,86
\end{tabular}

**Significativo a $1 \%$ de probabilidade, pelo teste $\mathrm{F} ;{ }^{\text {ns }}$ - Não significativo.

A variável massa seca de plantas daninhas não foi um parâmetro eficiente para seleção de pontas de pulverização, bem como para definições de doses de glyphosate. Já que, não conseguiu identificar ou separar nenhum tratamento, como foi obtido com a avaliação visual de controle das espécies daninhas.

\section{CONCLUSÕES}

Com exceção da ponta XR 110 02, as demais pontas (Al, TT e TJ-60) apresentaram melhor controle de plantas daninhas até os 21 DAA. Entretanto, aos 28 DAA a Al não diferiu estatisticamente da XR na avaliação do controle de plantas daninhas. As doses de glyphosate mais eficientes para a dessecação das plantas daninhas foram as superiores a $720 \mathrm{~g}$ i.a. ha ${ }^{-1}$.

\section{REFERÊNCIAS}

1. BASLER, E.; TODD, G. W.; MEYER, R. E. Effects of moisture stress on absorption, translocation and distribution of 2,4-dichlorophenoxyacet acid in bean plants. Plant Physiology, v. 36, p. 573-579, 1961.

2. BOSTRÖM, U.; FOGELFORS, H. Response of weeds and crop yield to herbicide dose decision-support guidelines. Weed Science, v. 50, p. 186-195, 2002.

3. BOYDSTON, R. A. Soil water content affects the activity of four herbicides on green foxtail. Weed Science, v. 38, p. 578-582, 1990.

4. CARMONA, R. Problemática e manejo de bancos de sementes de invasoras em solos agrícolas. Planta Daninha, v. 10, p. 5-16, 1992.

5. CARVALHO, A.M. de; SODRÉ FILHO, J. Uso de adubos verdes como cobertura do solo. Planaltina: EMBRAPACPAC, 2000. 20 p. (Boletim de Pesquisa, 11).

6. CHRISTOFOLETTI, J. C. Considerações sobre a deriva nas pulverizações agrícolas e seu controle. São Paulo: Teejet South América, 1999.

7. COSTA, N.V.; RODRIGUES, A.C.P.; MARTINS, D.; CARDOSO, L.A.; SILVA. J.I.C. Efeito de pontas de pulverização na deposição e na dessecação em plantas de Brachiaria brizantha. Planta Daninha, Viçosa-MG, v. 26, n. 4, p. 923 933, 2008.

8. DEVINE, M.D.; BANDEEN, J.D.; MCKERSIE, B.D. Temperature effects on glyphosate absorption, translocation and distribution in quackgrass (Agropyron repens). Weed Science, Champaign, v.31, p.461-464, 1983. 
BARROS, M. P. C. et al. Controle de plantas daninhas...

9. DEVLIN, D. L.; LONG, J. H.; MADDUX, L. D. Using reduced rates of postemergence herbicides in soybeans (Glycine max). Weed Technology, v. 5, p. 834-840, 1991

10. FERNANDES, H.C. Aplicação de defensivos agrícolas: Teoria da gota. Engenharia na Agricultura, Viçosa, 1997. 14p. Caderno Didático 24.

11. FERREIRA, D. F. SISVAR 4.0 Copyright. Lavras: UFLA/DEX, 1999-2000.

12. HESS, F. D. Mechanism of action of inhibitors of amino acid biosynthesis. In: Herbicide action: an intensive course on the activity, selectivity, behavior, and fate of herbicides in plants and soil. West Lafayette: Purdue University, 1994. p. 344-365.

13. JENSEN, P. K.; LUND, I. Static and dynamic distribution of spray from single nozzle and the influence on biological efficacy of band application of herbicides. Crop Protection, Lincoln, v.25, n., p. 1201-1209, nov. 2006

14. KLINGAMAN, T. E.; KING, C. A.; OLIVER, L. R. Effect of application rate, weed species, and weed stage of growth on imazethapyr activity. Weed Science, v. 40, p. 227-232, 1992.

15. KRUSE, N.D.; TREZZI, M.M.; VIDAL, R.A. Herbicidas inibidores da EPSPs: revisão de literatura. Revista Brasileira de Herbicidas, Brasília, v.1, n.2, p.139-146, 2000.

16. LANDERS, J. N. 1994. Fascículo de experiência de plantio direto no cerrado. Goiânia, GO. 261p.

17. LEVENE, B. C.; OWEN, M. D. K. Effect of moisture stress and leaf age on bentazon absorption in common cocklebur (Xanthium strumarium) and velvetleaf (Abutilon theophrasti). Weed Science, v. 43, p. 7-12, 1995.

18. PERECIN, D.; PERESSIN, V.A.; MATUO, T.; BRAZ, B.A.; PIO, L.C. Padrões de distribuição de líquidos obtidos com bicos TF-VS4, TJ60-11006 e TQ15006 em mesa de prova. Pesquisa Agropecuária Brasileira, Brasília, DF, v.33, n.2 1998.

19. PEREGOY, R. et al. Moisture stress effects on the absorption, translocation, and metabolism of haloxyfop in johnsongrass (Sorghum halepense) and large crabgrass (Digitaria sanguinalis). Weed Science, v. 38, p. 331-337, 1990. RODRIGUES, B. N.; ALMEIDA, F. S. Guia de herbicidas. 3.ed. Londrina: IAPAR, 2005. 591 p. RODRIGUES, B. N.; ALMEIDA, F. S. Guia de herbicidas. Londrina: Edição dos Autores, 1998. 648 p.

SANTOS, I. C. et al. Eficiencia de glyfosate no controle de Commelina benghalensis e Commelina difusa. Planta Daninha, Viçosa, v.19, n.1, p.135-143, 2001.

23. SIKKEMA, P. H.; BROWN, L.; SHROPSHIRE, C.; SPIESER, H.; SOLTANI, N. Flat fan and air induction nozzles affect soybean herbicide efficacy. Weed Biology and Management, Kyoto, v.8, n. 1, p. 31-38, mar. 2008.

24. SILVA, O.C. Tecnologia de aplicação de fungicidas. In: CANTERI, M.G.; PRIA, M.D.; SILVA, O.C. (eds.). Principais doenças fúngicas do feijoeiro. Ponta Grossa: UEPG, 1999. p.127-137.

25. WOMAC, A. R.; GOODWIN, J. C.; HART, W. E. Comprehensive evaluation of droplet spectra from drift reduction nozzles. St. Joseph: ASAE, 1997. 